\title{
Erratum to: Participatory Sensing, Opinions and Collective Awareness
}

\author{
Vittorio Loreto, Muki Haklay, Andreas Hotho, Vito D.P. Servedio, \\ Gerd Stumme, Jan Theunis, and Francesca Tria
}

\section{Erratum to:}

V. Loreto et al. (eds.), Participatory Sensing, Opinions and Collective Awareness, Understanding Complex Systems, DOI 10.1007/978-3-319-25658-0

(C) Springer International Publishing Switzerland 2017

The publisher regrets to inform that the initial for one of the book editors was incorrect. The correct name is Vito D.P. Servedio (wrong: Vito C.P. Servedio).

The updated online version of the original book can be found under DOI 10.1007/978-3-319-25658-0 